\title{
Study on Industry Cluster of Shipping Industry in the City of Zhoushan
}

\author{
Yao Yao \\ Hangzhou Institute of Service Engineering, Hangzhou Normal University, Hangzhou, 311121, China \\ yyaoexist@163.com
}

Keywords: Industry cluster; Shipping industry; The city of Zhoushan; Innovation

\begin{abstract}
The industry cluster of shipping in the city of Zhoushan has been developing rapidly. It is crucial in marine economy, and plays an important role in the economic development in Yangtze river delta economic zone. This paper addresses the issues in the development of shipping industry, the problems in innovation and technology, human resources and expertise, industry concentration and competitiveness, supporting industry are analyzed. Then the paper discusses corresponding coping strategies, which include production capacity, technology innovation role of government, mode of development.
\end{abstract}

\section{Introduction}

Industry cluster is a geo-economic issue, which indicate concentrated industry gives comprehensive competitiveness of the industry by technology and efficiency. Shipping industry in Zhoushan, which developed rapidly in this decade, is an important industry cluster in Zhejiang Province. It also plays an important role in Yangtze-river delta economic zone in marine economy. The resources flowed into Zhoushan over the past decade, include human resource, logistics, information, because of the impact of bridge effect. Shipping companies, including some international corporations relocated to Zhoushan. In the background of global industry transformation and upgrading, during the economic integration in Yangtze river delta economic zone, marine economy is considered strategically important, and shipping industry cluster in Zhoushan is well supported. Analysis on the development, the issue and strategy of the industry cluster would shed light on the marine economy of Zhoushan, and the role of the industry cluster in the economic development. The paper is structured as follows: the first section gives the research background of the paper; the second section examines technology, innovation and sustainable development of shipping industry in the city of Zhoushan; the third section addresses some issues in the development of shipping industry in Zhoushan; the fourth section give some corresponding strategies to cope with the afore said issues; then the last section concludes.

\section{Innovation and Sustainable Development of Shipping Industry Cluster in Zhoushan}

Technology and innovation ability is determinate factor in international competitiveness of shipping industry. Macro variables, such as exchange rate volatility and cyclical fluctuation of market, increases potential risk in shipping industry. It is necessary for shipping companies to promote their technology and skill, to improve their risk management ability. Sustainable development of shipping industry in Zhoushan requires a innovation system in ship building. The role of government in regulation and providing services could accompanies with interaction and leading innovation through platform connects research institutions, universities and shipping companies.

Innovation Environment.To promote innovation in shipping industry, make full use of industry cluster would be necessary. Support from the government, and organization culture that value innovation, could form an atmosphere that encourage innovation in the shipping industry in the city of Zhoushan. From business aspect, to establish and perfect a firm management system that value, encourage and reward innovation, to improve potential power in the industry. From government aspect, promote cooperation amongst firms and research institutions, organize periodical events of shipping building technology and skills. Commerce and industrial organizations could also help prometing 
innovation. Organizations like Zhoushan shipbuilding industry association provide a platform for all parties to participate in different aspects in the development of industry, could facilitate communications and discussion in the issue of innovation.

The Coordinated Innovation. The local universities and research institutions could provide the shipping industry in the city of Zhoushan with technological and skill workers, as well as innovation power. The shipping building companies are the centre of innovation, and executer of technology. Coordinated development amongst firms, institutions and universities, could contribute to the establishment of the innovation system in shipping industry. The universities and research institutions are source of innovation of technology and skills. The market perspective and industry insight of entrepreneurs would contribute to theory analysis of the researchers. Successful transfer of science and technology achievements into economic entities, channel research from universities and research institutions into the industry, is crucial in sustainable development of the industry.

Technology Foresight. Technology foresight plays an important role in future development of the industry. The foresight of long term development of the industry, the future technology and economic and social development in general, would direct innovation in the industry in the right direction. The understanding of development trend of shipping building techonology and the industry in general help the firms to research and acquire necessary technology.

Digitalization. Promotion of information technology would be necessary in the foreseeable future. Improve the information level of the shipping building industry, gradually establish modernized mode of ship building. Digitalization of the industry would improve aggregate skill level of the industry, such like digital shipping design technology, digital management and ship building. Optimization of the structure of shipping industry, promote development in strategic sector in oceanic engineering. Acquiring key technology, cultivate independent research capability, would contribute to international competitiveness of shipping in dustry in Zhoushan.

\section{The Issues in the Development of Shipping Industry in Zhoushan}

Despite the rapid expansion of the shipping industry in Zhoushan, there are several issues in the industry cluster which would be crucial in the future development.

Innovation Capability in Technology. The technology support of the shipping companies in Zhoushan is relatively weak. The technology and skill is less than sufficient to support sustainable innovation. The businesses emphasize more on scale expansion rather than the industrial technology innovation, which become an issue in industry transformation and upgrading. The lack of the ability in ship design, technical storage and management in ship building and repairmen companies impedes the overall upgrading and development. Most companies have not yet adopt modern shipping building model. The input on research and development is severely insufficient, with some companies has next to zero input in technology, which result in long building cycle and low efficiency. Only a few companies have design departments, most companies have to outsource ship design overseas.

Expertise and Human Resources. The lack of expert and professionals in shipping industry constrains the development of the industry. There is a lack in the experts of shipping industry in the field of technology, management and research in Zhoushan. At present most experts and technology personnel in the industry are from universities and research institutions out of Zhoushan. Other technical and managerial staff are from Shanghai and Jiangsu. The shipping industry in Zhoushan requires a more stable and more reasonably structured talent team.

Industry Concentration and Competitive Ability. The shipping companies in Zhoushan are mostly small-sized, decentralized and in the lower position in the industrial chain. The degree of industry concentration is relatively low, while the competitive strength is not enough. Except for several companies with relatively larger scale, such as Cosco Shipyard, Zhejiang Ouhua Ship building corporation, Tsuneishi Group Ship building, Zhoushan Jinhaiwan Shipyard corporation and Yangfan Group, most small shipping companies have low capability in ship building and repair, result in low competitiveness and less than satisfactory performance. Most small sized shipping companies still 
applies out of date method in ship building and requirement. With large numbers of shipping companies, each include all businesses yet excel in none, is a problem in the shipping industry in Zhoushan.

Supporting Industry. The supporting industry of shipping in Zhoushan is underdeveloped. The lag between the rapid growth of shipping industry and its support industry has become an impediment. Imbalanced development and low localization rate will undermine the comprehensive competitiveness of shipping industry in Zhoushan. The underdevelopment of supporting industry is a result of low innovation capability of the local shipping companies. Lack of key technology, the shipping companies in Zhoushan could not support the research and development of supporting industry. Meanwhile, the supporting industry of shipping in Zhoushan has lower than state average localization rate. Most supporting industry is provided by neighboring Jiangsu Province. But the technology level of supporting industry, th quality of equipment comprises of crucial part of shipping industry, and has an immediate impact on export competitiveness of shipping industry in Zhejiang.

\section{The Strategies in the Shipping Industry in Zhoushan}

The Bridge Effect. Promoting ship building industry cluster with the bridge effect, is an geo-economic strategy in Zhoushan. Promote the resources from Ningbo and Shanghai, such as funds, industry, technology and human resources, to transfer to Zhoushan. Meanwhile, enhance the interrelationship between industries in Shanghai, Ningbo, Taizhou and Zhoushan. With bridge effect, Zhoushan could further expand the scope of industry cluster and make full use of complementary advantage. Enhancing industry competitive advantage on shipping industry distribution, industry base and site, coastal resource, cargo loading and energy, Zhoushan could plan industry distribution with district and industry characteristic. Thus, Zhoushan could promote shipping industry in the area, by promoting initiative, radiation and competitiveness in industry cluster.

Production Capacity. Adopt modern ship building model, promote corporation's production capacity. Promote process reengineering, bring automation, digitalization and streamlining into ship building process. Meanwhile, developing supporting industry, extending industrial chain, would also be necessary. Based on overall optimization theory, applying the principle of group technology, guided by intermediate produces, organize production by region with time order, so as to extensively promote modern ship building mode.

Technology Innovation. Shipping companies could build and maintain corporation relations with famous international ship manufacturers, with various mutually beneficial methods such as license or joint production. In the international corporation, the local companies could learn from their overseas partners and obtain advanced technology and management experience. To corporate with European partners is more favorable, considering Europe being the most important export destination of shipping from Zhoushan. Meanwhile, re-innovation based on imported technology is also important. Research bodies and strategic alliances are called for, combining different organizations in shipping building and supporting industry, such as multi-national corporations, large corporation headquarters, research and develop base, research institutions and universities. The companies in Zhoushan with technology disadvantage can thus make full use of late development advantage, promoting all shipping companies to participate in innovation activities. Establishing a human resource introduction and cultivating system, enhancing independent innovation ability of local companies, so as to achieve industry optimization and upgrading. Bring in talent introduce competition mechanism and creative salary system. The research and development department in companies should be supported, while regional and industrial research centered should be established.

The Role of Government. The role of government in providing positive industry development environment is crucial. Policy measures would be necessary to promote ocean, coastal, inland waterway ship, ocean engineering and shipping supporting products altogether, so as to from a new industry framework, featured by complementary advantage, mutual promotion and co-development. International shipping exhibitions, project promotion events and other international communicating 
platform would be provided by the government, to promote more value-added, larger scale, more competitive project.

Government could promote industry competitiveness and profitability by integrating existing resources, to integrate production capability of small and medium sized companies, promote efficiency of infrastructure and coastal resources, by various methods such as merger and acquisition, combination, transformation and relocation. Government should help to provide sufficient funds for the development of the industry, Promoting cooperation between financial institutions and shipping companies, providing financial services and support to shipping companies, such as ship export insurance, financing, export loan, preferential taxation. Government would provide a healthy and positive environment, by promoting competition and cooperation amongst firms, building network of shipping companies and supporting industry companies, establishing open competitive system and corresponding credit system.

Mode of Development. Green development strategy would be important in shipping industry in Zhoushan. to protect environment, during the building and repair of shipping, environmental design, innoxiousness material, high efficiency technology, pollution protection facilities, recycling spare parts and other measures should be taken.Differentiate development strategy would give Zhoushan a wedge in shipping industry. To form a unique shipping industry framework, Zhoushan could apply its unique feature. Unlike other shipping industry centre such as Taizhou and Wenzhou, Zhoushan could emphasize more on the ocean engineering, offshore oil and gas development.

\section{Conclusion}

The industry cluster in Zhoushan shipping industry has developed rapidly in the past decade. The industry cluster is crucial in marine economy in Zhejiang Province, and it plays an important role in the economic development in Yangtze river delta economic zone. This paper analyzes innovation and sustainable development of the industry, examines the strategies to promote technology innovation. This paper addresses some issues in the development of shipping industry, and then gives some coping strategies. The issues include innovation and technology, human resources and expertise, industry concentration and competitiveness, supporting industry are discussed. The coping strategies, which include production capacity, technology innovation role of government, mode of development would be crucial in the future development of the industry cluster in shipping.

\section{Acknowledgement}

This study is supported by the Natural Science Foundation of Zhejiang Province, Research on financial time series data mining, LQ15F020013.

\section{References}

[1] A.E. Zamora, Value Chain Analysis: A Brief Review, Asian Journal of Innovation \& Policy. 5 (2016) 116-128.

[2] A. Rolv Petter, B. Ove.Globalization and the Development of Industrial Clusters: Comparing Two Norwegian Clusters, 1900-2010.Business History Review, 89 (2015), 693-716.

[3] R. Martin, R. Florida, M. Pogue, C. Mellander, Creativity, clusters and the competitive advantage of cities. Competitiveness Review. 25(2015), 482-496.

[4] Y.Zhang, L.J.S Lee, Estimating economic losses of industry clusters due to port disruptions, Transportation Research Part A: Policy \& Practice. 91 (2016) 17-33.

[5] T.J.Webster, Malaysian economic development, leading industrial clusters. Singapore Economic Review, 59 (2014) 1-19. 
[6] L. Sarach, Analysis of Cooperative Relationship in industrial Cluster, Procedia - Social and Behavioral Sciences, 191 (2015), 250-254.

[7] B. Alexander, K. Tatiana, U. Svetlana, Formation of industrial Clusters Using Method of Virtual Enterprises, Procedia Economics and Finance, 5 (2013) 68-72.

[8] I. Kaygalak, N. Reid, The geographical evolution of manufacturing and industrial policies in Turkey, Applied Geography, 70 (2016) 37-48.

[9] Information on http://www.zhoushan.cn/

[10] Information on http://zs.96871.com.cn/ 